\title{
Aplikasi Multimedia Interaktif pada Pembelajaran Metode Tilawati Berbasis Web Responsive
}

\section{Interactive Multimedia Application on Tilawati Learning on Responsive Web}

\author{
Aminudin ${ }^{1}$, Zamah Sari' ${ }^{2}$, Setio Basuki ${ }^{3}$ \\ 1,2,3)Program Studi Teknik Informatika, Fakultas Teknik \\ Universitas Muhammadiyah Malang \\ Jl. Raya Tlogomas Malang 65144, Indonesia. \\ email: ${ }^{* 1}$ aminudin2008@umm.ac.id, ${ }^{2}$ zamah.sari@umm.ac.id, ${ }^{3}$ setio_basuki@umm.ac.id
}

DOI;
10.30595/jrst.v3i1.3964

Histori Artikel:

Diajukan:

25/01/2019

Direvisi:

10/02/2019

Diterima:

15/02/2019

\begin{abstract}
ABSTRAK
Taman Pendidikan Al-Quran (TPQ) merupakan sebuah lembaga pendidikan untuk mendidik santri agar dapat membaca Al-Quran sesuai dengan aturan yang berlaku. Salah satu metode yang dapat dipakai untuk belajar membaca Al-Qu'an dengan baik dan benar adalah Metode Tilawati. Metode Tilawati menawarkan suatu sistem pembelajaran Al-Qur'an yang yang mudah, efektif dan efesien demi mencapai kualitas bacaan, pemahamanan dan implementasi Al Qur'an. Tidak dapat dipungkiri, bahwa kehadiran teknologi informasi juga mempengaruhi perkembangan pendidikan, salah satunya adalah pendidikan di dalam lingkungan TPQ. Salah satu kendala yang dihadapi oleh TPQ yang menggunakan metode tilawati ini adalah tidak adanya media pembelajaran yang dapat digunakan oleh santri untuk mengulang pembelajaran yang telah dilakukan oleh santri secara mandiri. Untuk mengakomodasi dari permasalahan tersebut maka dalam penelitian ini akan dibangun sebuah aplikasi multimedia interaktif berbasis teknologi informasi yang dapat mencocokan antara huruf teks dengan hasil rekaman dari buku tilawati.
\end{abstract}

Kata Kunci: TPQ, metode tilawati, aplikasi multimedia, web responsive.

\begin{abstract}
Children's education Al-Quran (TPQ) is an educational institution to educate the students to be able to read the Koran in accordance with the applicable rules. One method that can be used to learn to read Al-Qu'an with good and right is the method Tilawati. The method offers a system of learning Tilawati Quran that easily, effectively and efficiently for the sake of achieving the quality readings, pemahamanan and implementation of the Qur'an. Can not be denied, that the presence of information technology also influenced the development of education, one of which is education in neighborhoods TPQ. One of the obstacles faced by the method using TPQ tilawati this media is the absence of learning that can be used by students to repeat the study that has been done by students independently. To accommodate the problem of then in this research will be an interactive multimedia-based applications of information technology that can match the right between the letters of the text with a recording of the book tilawati.
\end{abstract}

Keywords: TPQ, tilawati method, multimedia application, responsive web.

\section{PENDAHULUAN}

Pada saat ini di dalam mempelajari AlQuran ada banyak metode yang dapat digunakan untuk belajar Al-Quran salah satu contohnya adalah Metode Tilawati. Metode tilawati ini disusun pada tahun 2002 oleh tim terdiri dari Drs. 
H. Hasan Sadzili, Drs. H. Ali Muaffa dkk. Metode Tilawati ini terdiri dari 6 buah modul dan dipilih dengan alasan mengharuskan pengucapan secara baik dan benar. Tilawati menawarkan suatu sistem pembelajaran Al-Qur'an yang yang mudah, efektif dan efesien demi mencapai kualitas bacaan, pemahamanan dan implementasi Al Qur'an. Metode Tilawati menggabungkan metode pengajaran secara klasikal dan privat secara seimbang sehingga pengelolaan kelas lebih efektif. Kelebihan metode ini yaitu: (1) Menyeimbangkan pendekatan pembelajaran secara klasikal dan individual, (2) Metode ini disusun secara praktis sehingga mudah dipelajari, (3) Menekankan pada kemampuan peserta didik untuk dapat membaca al-Qur'an secara tartil, dan (4) Menggunakan variasi lagulagu tilawah dalam membaca al-Qur'an sehingga tidak membosankan. Dengan penerapan lagu dalam bacaan Al-Qur'an siswa akan lebih senang dalam proses pembelajaran dan gemar membaca Al-Quràn sehingga berdampak pada hasil belajar siswa (Luthfi, 2015).

Taman Pendidikan Al-Quran (TPQ) merupakan sebuah lembaga pendidikan untuk mendidik santri agar dapat membaca Al-Quran sesuai dengan aturan yang berlaku (Umar dkk, 2015). Pembelajaran TPQ tidak terdapat batas usia untuk menjadi santri, maka tidak heran jika terdapat santri yang masih berusia sangat muda (4 tahun) telah menyelesaikan seluruh modul pembelajaran, dan santri yang lebih tua (8 tahun) yang baru memulai mempelajari Al-Quran. Untuk dapat dikatakan lulus, santri diwajibkan mengikuti tes baik yang diuji oleh pengajar maupun kepala TPQ untuk setiap modul (Dainuri, 2017).

Terdapat beberapa faktor yang mempengaruhi kecepatan pemahaman terhadap sebuah materi belajar yaitu tingkat kecerdasan, motivasi santri, metode pengajaran, dan fasilitas pembelajaran. Hampir seluruh santri di tempat mitra hanya melakukan pembelajaran ketika berada pada TPQ. Yang menjadi kendala bagi santri untuk mengulang kembali pelajaran atau bahkan mempersiapkan diri lebih dini untuk mempersiapkan ujian adalah bahwa tidak terdapat media alternatif selain buku teks modul Tilawati.

Selain itu santri tidak memiliki fasilitas untuk mengulang pembelajaran yang telah dilakukan di TPQ atau mengecek bentuk bacaan yang dia baca sudah benar atau salah hal ini dikarenakan tidak semua orang tua santri dapat mengkoreksi bacaan tersebut atau dalam bahasa santri nya 'nyemak'. Permasalahan selanjutnya terkait dengan motivasi santri yang rendah untuk mempelajari metode Tilawati. Buku panduan yang dimiliki santri tidak terlalu dapat meningkatkan minat belajar santri. Harapannya adalah terdapat suatu media belajar alternatif bagi santri TPQ untuk dapat mengakselerasi kemampuan baca Al-Quran. Media yang diinginkan adalah berupa media interaktif yang dikembangkan dengan metode tertentu yang dapat menarik minat santri untuk pembelajaran dan pemantapan metode Tilawati secara mandiri (Rizal, 2012). Selain dapat digunakan oleh santri, media alternatif ini dapat pula dimanfaatkan oleh anak belum menjadi santri TPQ atau bahkan orang dewasa yang hendak mempelajari teknik baca Al-Quran dengan metode Tilawati. Dengan demikian, seluruh proses untuk menyelesaikan seluruh modul Tilawati dapat di reduksi (Luthfi, 2015).

Perkembangan teknologi informasi beberapa tahun terakhir juga merambah pada dunia pendidikan salah satu contoh adalah penerapan teknologi di dalam proses pembelajaran TPQ. Penerapan teknologi tersebut digunakan untuk pembuatan media sebagai sarana penyajian ide, gagasan dan materi (Een, 2017). Dengan melihat realitas yang ada, dimana semakin hari, umat islam yang tidak bisa membaca Al-Qur'an semakin banyak dan belum lagi yang belum faham akan makna serta kandungan Al-Qur'an, maka para aktifis yang sudah lama didalam TPA atau TPQ terdorong untuk membuat suatu metode pembelajaran AlQur'an yang diharapkan dapat mudah dipelajari (Rizal, 2012).

Berdasarkan permasalahan yang sudah dipaparkan diatas, maka pada penelitian ini akan dikembagnkan suatu aplikasi berbasis multimedia interaktif untuk mengakomodasi kebutuhan dari beberapa masalah yang telah diuraikan diatas. Aplikasi yang akan dibangun melibatkan beberapa komponen media seperti text dan suara. Beberapa fungsi yang dapat diperoleh dari aplikasi ini adalah (1) ekstraksi inti dari metode Tilawati setiap modul, (2) Mind Mapping dari keseluruhan materi yang disajikan untuk setiap modul yang dicocokan dengan suara. Perangkat lunak yang diusulkan adalah aplikasi teks yang bergerak didasarkan atas suara modul tilawati dengan mind mapping seluruh modul tilawati. Perangkat lunak yang dibangun berbasis web responsive artinya aplikasi tersebut dapat 
berjalan tablet, HP dan desktop tanpa mengubah ukuran aplikasi dan aplikasi ini bersifat online jadi aplikasi ini dapat digunakan kapan saja dan dimana saja (Aminudin, 2015).

\section{METODE PENELITIAN}

Pada bagian ini akan dijelaskan alur pelaksanaan penelitian dimulai dari pengumpulan dataset, arsitektur dan rancangan pengujian.

\subsection{Data Penelitian}

Data yang digunakan di dalam penelitian ini adalah hasil dari ekstraksi dan hasil mapping atau pemetaan serta pengkategorian masingmasing jilid dan halaman yang didasarkan pada seluruh jilid yang ada di dalam buku Tilawati. Di mana masing-masing di jilid di dalam buku tersebut terdiri satu jilid ada 44 halaman dan di dalam satu buku tilawati terdapat 6 jilid. Disamping itu, aplikasi yang dibangun di dalam penelitian ini juga berbasis multimedia yang dapat mencocokan antara suara dengan ekstraksi buku, maka di dalam penelitian ini juga merekam salah satu ustadz senior Tilawati berdasarkan buku tilawati. Gambar 1 menunjukkan dataset yang digunakan buku tilawati dalam penelitian ini.

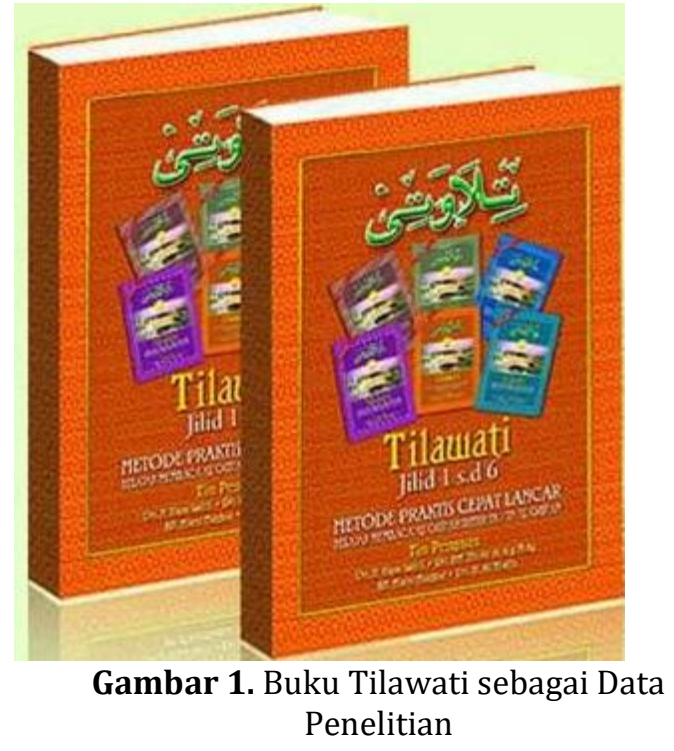

Berdasarkan dari Gambar 1 buku tilawati yang dijadikan acuan untuk pemetaan dan pembagian masing-masing jilid. Ada 6 jilid di dalam buku tilawati tersebut, masing-masing jilid dibedakan kategori berdasarkan kemampuan di dalam membaca Al-Qur'an. Jilid 1 bersifat dasar yang dimulai dari huruf Hijaiyyah sampai dengan beberapa huruf yang tersambung. Jilid 2 sd 4 pengenalan tingkat sedang sampai dengan pengenalan tajwid dan jilid yang ke 5 dan 6 sudah masuk ke dalam tahap tingkat lanjut di mana di dalam jilid tersebut sudah banyak ayat-ayat AlQur'an di dalamnya. Adapun data perekaman suara ditunjukan dalam Gambar 2 berikut.

Gambar 2. Contoh Suara Rekaman untuk

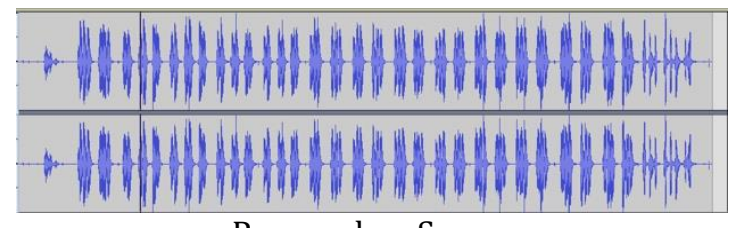

Pencocokan Suara

\subsection{Ekstraksi Pencocokan Suara dengan Buku Teks}

Salah satu fitur utama di dalam Aplikasi Tilawati ini adalah adanya fitur pencocokan suara dengan huruf pada buku teks Tilawati. Maka dari itu, dibutuhkan sebuah teknik di dalam pembuatan aplikasi untuk pencocokan suara dengan huruf. Teknik yang digunakan adalah Ekstraksi. Ekstraksi digunakan untuk mencocokan antara suara dengan teks buku tilawati dengan menggunakan konsep pelabelan. Di dalam pencocokan suara dan teks penelitian ini menggunakan Software dengan nama Audacity. Pencocokan suara dengan teks didasarkan atas waktu pergerakan suara. Adapun tampilan hasil konversi antara suara dengan buku teks dapat ditunjukan pada Gambar 3 berikut.

$\begin{array}{cc}35.015692 & 34.202993 \\ 35.979320 & 35.236281 \\ 36.768798 & 35.979320 \\ 38.510295 & 37.999456 \\ 38.986304 & 38.510295 \\ 39.961542 & 38.986304 \\ 40.960000 & 40.425941 \\ 41.482449 & 40.960000 \\ 42.260317 & 41.482449 \\ 43.688345 & 43.107846 \\ 44.210794 & 43.688345 \\ 45.174422 & 44.210794 \\ 46.138050 & 45.592381 \\ 46.706939 & 46.138050 \\ 47.577687 & 46.706939 \\ 49.330794 & 48.773515 \\ 49.795193 & 49.330794 \\ 50.770431 & 49.795193 \\ 51.815329 & 51.258050 \\ 52.326168 & 51.815329 \\ 53.069206 & 52.326168 \\ 55.112562 & 54.334694 \\ 56.018141 & 55.112562\end{array}$

Gambar 3. Proses Pencocokan Suara dengan Buku Teks Menggunakan Labelling

Gambar 3 menunjukan hasil ekstraksi pencocokan suara dengan teks yang didasarkan atas waktu. Jika dilihat pada Gambar 3 didapatkan waktu yang dibutuhkan untuk pengucapan salah 
satu huruf adalah antara waktu sekian sampai sekian.

\subsection{Alur Rancangan dan Arsitektur Aplikasi}

Adapun rancangan secara rinci proses pembangunan aplikasi tilawati dari pengumpulan dataset sampai aplikasi tilawati dapat berjalan ditunjukan pada Gambar 4 berikut.

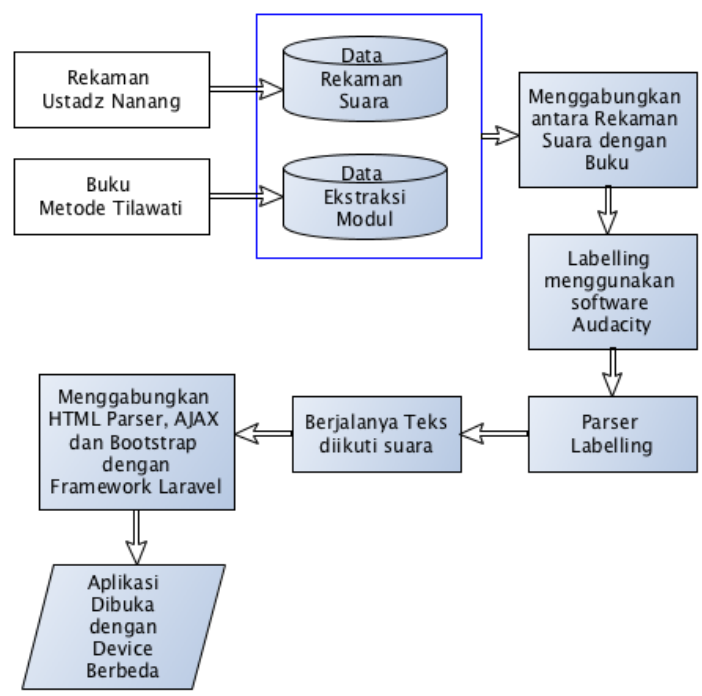

Gambar 4. Alur Proses Pembuatan Aplikasi

Berdasarkan Gambar 4 menunjukan bahwa data yang dikumpulkan ada dua yaitu data mapping buku Tilawati dan data hasil rekaman berdasarkan modul tilawati. Untuk mengakomodasi kebutuhan tersebut maka dalam kegiatan ini kami merekam salah satu ustadz yang sudah senior dan juga pengurus Tilawati cabang Malang Ustadz Nanang QZ. Selanjutnya untuk menggabungkan antara rekaman suara dengan teks buku modul tilawati maka dibuat labelling dengan menggunakan software Audacity. Aplikasi multimedia interaktif menggunakan metode tilawati dibuat menggunakan framework Laravel, dikarenakan framework Laravel merupakan salah satu framework yang lagi trend dikalangan webmaster karena didukung banyak fungsionalitas yang ada di dalam framework tersebut. Langkah pertama yaitu Pembuatan UX (User Experience) yang interaktif dan berbasis multimedia hal ini dimaksudkan agar para santri yang notabene masih dalam tahap usia dini menyukai aplikasi ini.

Hasil dari mapping tiap-tiap modul di dalam buku Tilawati yang sudah ada dikonversi atau mengubah huruf asli arab asli ke kamputer, karena tampilan di dalam aplikasi tidak menggunakan buku yang discan maka kami akan mengubah seluruh isi buku Tilawati ke dalam huruf bahasa Arab di komputer. Kemudian hasil dari perekaman suara yang sudah kami lakukan pada bagian sebelumnya akan kami masukan ke dalam sistem kemudian di cocokan dengan huruf yang ada di dalam buku Tilawati. Jadi intinya antara suara dari Ustadz yang kami rekam tadi sesuai dengan huruf yang ada di dalam tampilan perangkat lunak. Untuk implementasi pencocokan tampilan huruf mapping jilid buku Tilawati dengan suara menggunakan teknologi web JQuery dan AJAX.

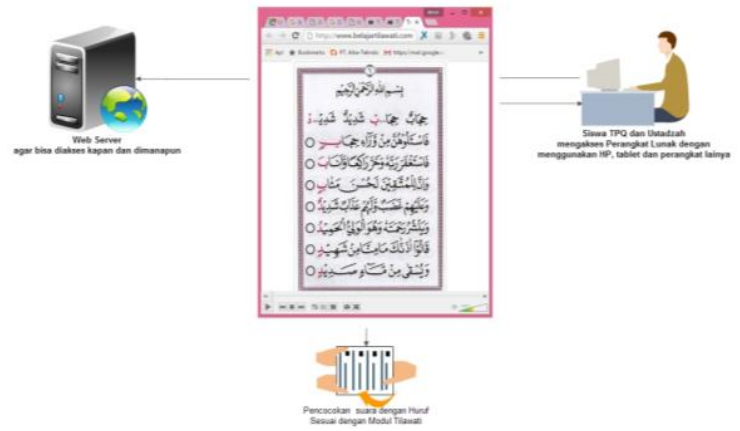

Gambar 5. Arsiketur Pembuatan Aplikasi

Pada Gambar 5 teknologi yang akan di bangun berbasis web base dan bersifat web responsive artinya teknologi tersebut bisa di buka dengan menggunakan laptop, desktop atau HP dan gadget lainya tanpa merubah konten dan tampilan sistem, di dalam sistem tersebut menyediakan sebuah kontent buku tilawati yang sudah di mapping berdasarkan jilid-jilid ke dalam aplikasi dan di cocokan dengan suara sesuai dengan metode tilawati yang biasa digunakan sebagai pembelajaran, sehingga mudah-mudahan dengan adanya aplikasi seperti yang sudah di jelaskan diatas bisa mempermudah bagi para santri TPQ dan orang awam yang ingin belajar membaca al-qur'an tetapi sibuk karena terkendala waktu untuk belajar langsung ke ustadz terkait.

\subsection{Alur Rancangan dan Arsitektur Aplikasi}

Pengujian dari aplikasi yang akan diterapkan pada penelitian ini adalah menguji kebenaran dan kemampuan aplikasi masingmasing fungsi yang ada di dalamnya dan menguji aplikasi tilawati pada masing-masing device yang berbeda untuk menguji kemampuan responsive 
aplikasi terhadap device yang ukuran layarnya berbeda.

\section{HASIL DAN PEMBAHASAN \\ 3.1 Implementasi Aplikasi}

Untuk mengimplementasikan sistem tilawati ini dibutuhkan sebuah spesifikasi komputer agar aplikasi tilawati dapat berjalan dengan baik. Perlu diketahui bahwa aplikasi tilawati yang sudah dibuat mendukung semua komponen komputer baik gadget HP dengan berbagai ukuran dan komputer serta laptop tanpa mengubah struktur interface yang sudah ada di dalam sistem tilawati. Hal ini dikarenakan di dalam sistem Tilawati sudah dikembangkan teknologi web yang berbasis web responsive. Artinya aplikasi tersebut dibuka dari berbagai perangkat tidak akan mengubah ukuran dan tampilan aplikasi. Untuk pengujianya peneliti melakukan beberapa percobaan dengan menggunakan perangkat yang berbeda, perangkat yang akan diujikan adalah sebagai berikut :

Tabel 1. Pengujian Aplikasi menggunakan berbagai macam perangkat

\begin{tabular}{ll}
\hline \multicolumn{1}{c}{ Perangkat } & \multicolumn{1}{c}{ Ukuran Layar } \\
\hline Laptop Mac & 13 Inch \\
HP Samsung Core 2 & $4.5 \mathrm{inc}$ \\
Samsung A3 2017 & 4.7 inch \\
\hline
\end{tabular}

\subsection{Hasil Aplikasi}

Aplikasi tilawati yang dikembangkan dibagi menjadi 3 user utama yaitu halaman user atau guest, halaman administrator dan halaman santri. Masing-masing user memiliki hak akses sendiri-sendiri. Hal ini dilakukan untuk menjembatani kepentingan dari masing-masing user.

\section{a. Halaman User Guest}

Halaman user didalam aplikasi tilawati ini dapat membaca berita yang terkait dengan kegiatan tilawati dan diposting oleh administrator. Sifatnya user guest di dalam aplikasi ini adalah membaca sehingga user yang mengunjungi aplikasi ini hanya dapat membaca artikel yang diposting oleh administrator.

\section{b. Halaman Administrator}

User administrator dapat melakukan manajemen user-user yang lain misalnya saja user santri dll. User administrator ini mempunyai otoritas penuh untuk melakukan setting dan manage aplikais tilawati ini seperti melakukan pendaftaran user, posting berita dan posting gambar slide show.

\section{c. Halaman Santri}

Halaman santri ini merupakan pokok tujuan dan manfaat aplikasi yang dibuat karena di dalam halaman ini terdapat ekstraksi seluruh modul tilawati dan suara hasil rekaman salah satu ustadz Tilawati. Didalam halaman ini pula terdapat antara modul tilawati yang dicocokan dengan suara rekaman tilawati, hal ini dimaksudkan agar para santri yang belajar mengetahui bagaimana cara membaca dasar pemahaman Al-Qur'an.

\subsection{Pengujian Aplikasi}

Pengujian black box merupakan pengujian yang berfokus pada spesifikasi fungsionalitas aplikasi yang dibangun. Pengujian Black Box lebih menitikberatkan hasil yang dituju tanpa memikirkan hal-hal yang terkait dengan proses internal misalnya saja, pemrograman, design, maintenance dan lain sebagainya. Hasil pengujian black box pada aplikasi ini ditampilkan di dalam Tabel 2 berikut :

Tabel 2. Hasil Pengujian Black Box

\begin{tabular}{llc}
\hline \multicolumn{1}{c}{$\begin{array}{c}\text { Detail } \\
\text { Pengujian }\end{array}$} & $\begin{array}{c}\text { Hasil yang } \\
\text { diharapkan }\end{array}$ & $\begin{array}{l}\text { Hasil } \\
\text { uji }\end{array}$ \\
\hline $\begin{array}{l}\text { Menampilkan } \\
\text { Statistik }\end{array}$ & $\begin{array}{l}\text { Menampilkan } \\
\text { data statistik } \\
\text { santri yang } \\
\text { sudah }\end{array}$ & $\begin{array}{c}{[\sqrt{ }]} \\
\text { Sesuai }\end{array}$ \\
& $\begin{array}{l}\text { terdaftar } \\
\text { Menampilkan } \\
\text { ekstraksi } \\
\text { modul }\end{array}$ & {$[\sqrt{ }]$} \\
Menampilkan & Sesuai \\
Modul Tilawati & {$[\sqrt{ }]$} \\
$\begin{array}{l}\text { Mencocokan } \\
\text { antara modul } \\
\text { Tilawati dengan }\end{array}$ & & Sesuai \\
hasil rekaman & & \\
ustadz & & \\
\hline
\end{tabular}

\subsection{Pengujian Responsive Web}

Pengujian responsive web merupakan salah satu model teknologi web yang memberikan tampilan yang optimal meskipun menggunakan device yang berbeda baik ukuran dan jenisnya. Teknologi responsive dapat melakukan adaptasi terhadap berbagai perangkat misalnya, HP dan komputer di mana kedua jenis devive tersebut mempunyai ukuran yang sangat berbeda. Sehingga dalam konteks tampilan aplikasi apabila teknologi yang digunakan untuk membangun aplikasi tidak menggunakan 
teknologi web responsive maka hal ini dapat mempengaruhi kinerja aplikasi termasuk soal interface, dan hasil akhirnya berimplikasi pada kesukaan dan ketenangan user yang memakai aplikasi tersebut. Hal ini yang menjadi dasar di dalam membangun aplikasi belajar tilawati untuk menguji menggunakan konsep pengujian responsive web. Diharapkan dengan adanya aplikasi berbasis responsive ini juga seperti aplikasi berbasis desktop di mana aplikasinya dibuka di platform dapat berjalan (Aminudin, 2015).

Pengujian ini dilakukan agar aplikasi dapat digunakan dapat semua tipe ukuran perangkat. Hal itu dikarenakan para pengguna di pihak TPQ mempunyai perangkat yang berbeda-beda untuk mengakses aplikasi ukuran layarnya berbedabeda. Sehingga para pengguna dapat menikmati aplikasi belajar Al-Qur'an ini seperti pada perangkat yang peniliti pakai untuk pengujian aplikasi ini. Adapun hasil pengujian responsive ditunjukan pada Tabel 3 dibawah ini.

Tabel 3. Hasil Pengujian Responsive Web

\begin{tabular}{|c|c|}
\hline Perangkat & Hasil \\
\hline $\begin{array}{l}\text { Laptop } \\
\text { Mac } \\
\text { Ukuran } \\
\text { Kayar } 13 \\
\text { Inch }\end{array}$ & 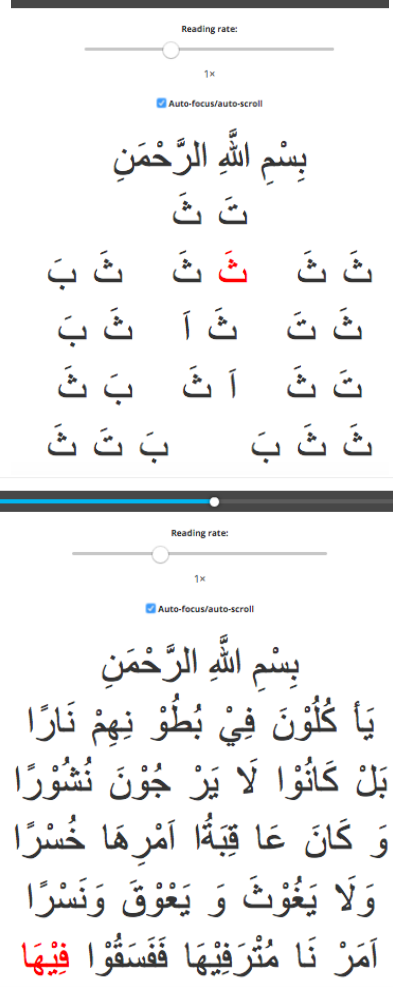 \\
\hline
\end{tabular}

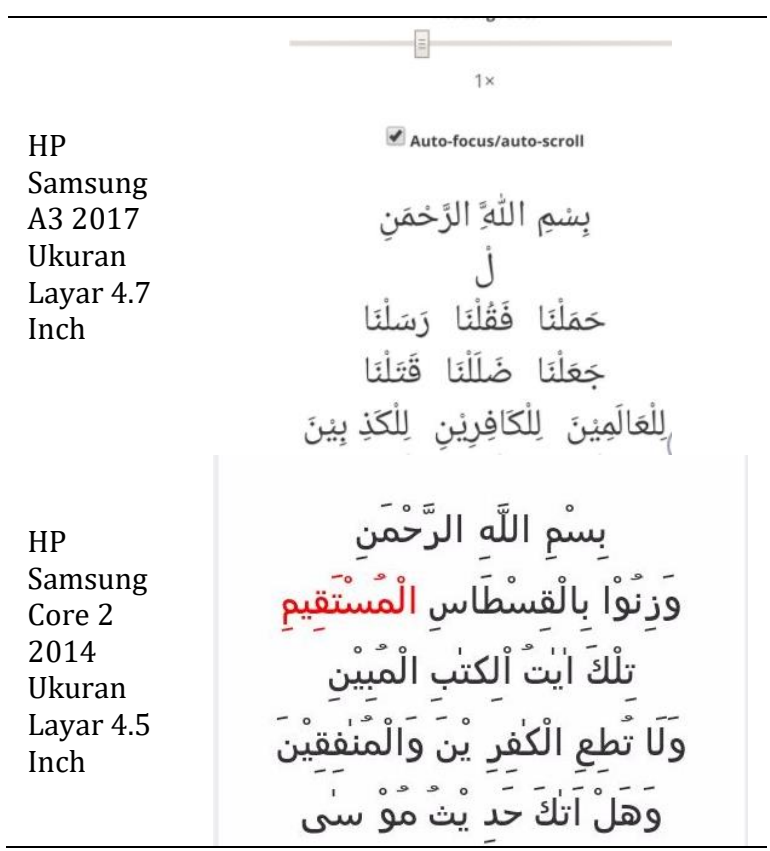

Hasil pengujian responsive aplikasi Tilawati pada berbagai perangkat didapatkan hasil bahwa aplikasi dapat berjalan dan tampil sesuai dengan yang diharapkan tanpa mengubah posisi view aplikasinya. Hal ini perlu dilakukan dikarenakan perangkat gadget sangat dinamis sekali, dan secara kebetulan untuk penerapannya agar siswa dan guru ketika akan belajar alternative pembelajaran ini dapat diakses dari berbagai perangkat yang berbeda.

\section{KESIMPULAN}

Berdasarkan dari pengujian yang telah dilakukan, maka dapat ditarik kesimpulan bahwa Aplikasi Tilawati yang dibangun dengan Framework Laravel berbasis Web Responsive dapat diimplementasikan dengan baik. Pengujian fungsionalitas sistem atau pengujian black box didapatkan hasil 100\% hasil kinerja sistem sesuai dengan yang diharapkan. Pengujian berbasis design web responsive didapatkan hasil 100\% tampilan sistem sesuai meskipun diakses dari device yang berbeda tanpa mengubah ukuran view sistem. Dari aplikasi yang sudah diimplementasikan dan dikembangkan ada beberapa hal yang dapat dikembangkan lebih lanjut lagi agar aplikasi tilawati ini dapat bermanfaat bagi masyarakat yaitu pencocokan antara suara rekaman dengan modul tilawati didasarkan perhuruf bukan perkata sehingga aplikasi yang dibuat benar-benar menunjukan hasil yang detail dari segi pembelajaranya. Dapat 
menggunakan teknologi parallel computing untuk mempercepat kinerja aplikasi web yang berjalan (Aminudin, 2019). Aplikasi yang akan dibangun dapat mengecek bacaan dari santri apakah sudah benar atau salah dengan menggunakan teknologi voice recognition dan algoritma Artificial Intelegence.

\section{DAFTAR PUSTAKA}

Luthfi, F., (2015). Metode Tilawati dalam Meningkatkan Kemampuan Membaca AlQur'an Santri Kelas 2 Madrasah Diniyah Ula Salafiyah Matholi'ul Huda Gading Malang, (Skripsi), Universitas Islam Negeri Maulana Malik Ibrahim Malang.

Umar, J. dkk., (2015). Peningkatan kemampuan membaca melalui metode tilawati dengan alat peraga kartu huruf hijaiyyah pada anak usia 4-5 tahun,

Dainuri (2015). Problematika Pembelajaran AlQuran dengan Metode Tilawati, in Annual Conference on Islamic Early Childhood Education.

Rizal, F., (2012). Modul Pembelajaran Al-Quran Berbasis Adobe Flash untuk Anak Usia

\section{UCAPAN TERIMA KASIH}

Penulis mengucapkan terima kasih kepada kepala lembaga tilawati wilayah Malang raya yang sudah mensupport pelaksanaaan penelitian aplikasi ini dan juga semua pihak di dalam Jurusan Teknik Informatika Universitas Muhammadiyah Malang yang telah memberikan dukungan motivasi di dalam menyelesaikan penelitian ini.

Dini Dengan Metode
Universitas Pembangunan
Veteran.

EEN, H., (2017). Implementasi metode tilawati dalam pembelajaran al- qur'an di madrasah (Penelitian Deskriptif di Madrasah Ibtidaiyah Pembangunan)), Pendidikan Agama Islam.

Aminudin, A., (2015). Cara Efektif Belajar Framework LARAVEL, I. Yogyakarta: Lokomedia.

Aminudin, A., (2019). ANALISA PERFORMA APACHE HADOOP DENGAN H2O MENGGUNAKAN BENCHMARK HIBENCH VIA CLOUD COMPUTING, in Prosiding SENTRA (Seminar Teknologi dan Rekayasa) 